\title{
Is reducing speed the right mitigating action to limit harmful emissions of seagoing RoRo cargo carriers?
}

\author{
Koos Frouws
}

\author{
Correspondence: j.w.frouws@tudelft.nl \\ Department of Maritime \\ Technology and Transportation, \\ Delft University of Technology, \\ Delft, the Netherlands
}

\begin{abstract}
The Energy Emission Design Index (EEDI) is an index indicating the $\mathrm{CO}_{2}$ emission per transportation effort, for example the emitted tons $\mathrm{CO}_{2}$ per ton mile, to be calculated for each new design. The required index for new designs will be gradually lowered in the coming years resulting in either improved energy efficiencies or speed reductions.

RoRo carriers are key stones in shore based logistical systems and as a result diverse in design speeds and main dimension ratio's. This diversity could be threatened by the relative simplicity of the EEDI regulations. This article aims to estimate the influence of the EEDI approach on 30 existing RoRo cargo carriers. The attained EEDI's per design are determined. Also the costs per transport effort are calculated based on the private costs and based on the social costs, both at the economically optimum speeds based on a uniformly applied sailing profile. The social costs are based on all emissions because the number of Environmental Special Area's is limited and the impact of speed reductions will not be limited to climate change. The expected speed reductions for these designs based on the EEDI, but also the required speed reductions when taking into account the total social costs are used to estimate the effectivity from the EEDI regulations. Amongst others it was concluded that the existing diversity in service speeds and main dimension ratio's will be jeopardized by the EEDI regulations.
\end{abstract}

Keywords: EEDI, External costs, Economic performance, Vessel, Ship, RoRo, Design, Maritime technology, Maritime economic, Emissions, Sustainability, Level playing field

\section{Introduction}

Emissions from ships are mostly emitted in a global context far from land. This combined with the fact that a new regulation requires the approval from many countries results often in a relatively slow process when developing and introducing emission reducing measures for the maritime world. Nevertheless, emission reduction has got its attention from the IMO, at first the sulphur and NOx emission reductions are regulated in the SECA areas. Finally there are now the new regulations for the $\mathrm{CO} 2$ emissions, regulated by means of the Energy Efficiency Design Index (EEDI). The fact that this has happened reflects the worldwide acceptance of the necessity of emission reducing measures.

(C) 2016 The Author(s). Open Access This article is distributed under the terms of the Creative Commons Attribution 4.0 International License (http://creativecommons.org/licenses/by/4.0/), which permits unrestricted use, distribution, and reproduction in any medium, provided you give appropriate credit to the original author(s) and the source, provide a link to the Creative Commons license, and indicate if changes were made. 
The essential goal of the EEDI regulations for new-buildings is decreasing the CO2 emissions per unit of transport capacity. The latter can be in principal a ton-mile or a cubic-meter-mile. This depends on the specific gravity of the cargo.

The principal formula used to express the index (Germanische Loyd, 2013) :

$$
\text { EEDI Attained }=\frac{\left\{\sum \mathrm{f}_{\mathrm{j}}\left(\mathrm{P}_{\mathrm{ME}(\mathrm{i})} \times \mathrm{C}_{\mathrm{FME}(\mathrm{i})} \times \mathrm{SFC}_{\mathrm{ME}(\mathrm{i})}\right)+\mathrm{P}_{\mathrm{AE}} \times \mathrm{C}_{\mathrm{FAE}} \times \mathrm{XFC}_{\mathrm{AE}}\right\}}{\mathrm{f}_{\mathrm{i}} \times \mathrm{f}_{\mathrm{l}} \mathrm{xf}_{\mathrm{w}} \times \mathrm{f}_{\mathrm{c}} \times \text { Capacity } \times \mathrm{V}_{\text {ref }}}
$$

With $\mathrm{P}_{\mathrm{ME}}=75 \%$ of the MCR of the main engine, the power required to create $\mathrm{V}_{\text {ref }}$ at trial condition.

The factor $f_{j}$ being a ship-type or specific design dependent correction factor.

The summation means that each Main Engine has to be taken into account separately. The parameters used in the equation are $\mathrm{P}_{\mathrm{ME}}, 75 \%$ of the installed power, $\mathrm{C}_{\mathrm{FME}}$ the $\mathrm{CO}_{2}$ emissions in ton per ton fuel and per type of fuel, the SFC (specific fuel consumption in gram per $\mathrm{kWh}$ ) of that specific engine. This, plus the emissions from the auxiliary engines determined by a statistical defined power consumption based on the installed main power. The rules describe corrections for the usage of PTO's (Power Take Offs) on the main engines, these corrections are not reflected in the formula above.

For Ro-Ro vessels the factor $f_{j}$ is defined as follows:

$$
\mathrm{fj}=\mathrm{f}_{\mathrm{jRoRo}}=\frac{1}{\mathrm{Fn}^{\alpha} \times(\mathrm{Lpp} / \mathrm{B})^{\beta} \times(\mathrm{Bm} / \mathrm{Ts})^{\gamma} \times(\mathrm{Lpp} / \sqrt{ } \nabla)^{\delta}}
$$

This function with the above shown parameters compensates for off standard main dimension ratio's and design speed variations. These are often the case with Ro-Ro vessels due to the specific services and conditions in which these vessels operate. These kind of corrections are not applied for Bulk carriers.

The capacity correction factors in the EEDI formula:

$\mathrm{f}_{\mathrm{i}}$ Correction for structural deadweight reducing design features. (safety, corrosion, iceclass and fatigue) The Ro-Ro EEDI has no Ice class correction.

$\mathrm{f}_{\mathrm{l}}$ Correction factor for general cargo ships

$\mathrm{f}_{\mathrm{w}}$ Correction factors for decreased speed at sea conditions at Beaufort 6 in order to calculate the EEDI weather. It has to be set on 1 for the normally attained EEDI calculation.

$\mathrm{f}_{\mathrm{c}}$ Deadweight correction factor for gas and chemical tankers.

The attained EEDI has to be less than the reference line expressed by the following formula:

EEDI reference $=\mathrm{a} \cdot \mathrm{b}^{-\mathrm{c}}$

With a and c constants defined per ship-type and b the design deadweight of the vessel. It is the intention to lower these reference lines each year, in 2015 with a total of $30 \%$. It has to be noted that this approach is focused on the design speed. The design speed in this paper is the speed with a clean hull, without added resistance due to waves and at approximately $75 \%$ of the maximum continuous rating of the engine. The $25 \%$ reduction is composed by two chosen factors, one to reduce the maintenance bill, often $10 \%$ and a sea margin most often $15 \%$. These figures suggest that you can just add them, however, the calculation is more complex. Intermediate speeds and their 
corresponding fuel consumption is an area which can often be substantially improved with sometimes large effects on the voyage costs.

\section{Research questions}

It seems a goal based regulation, not specifying the means. However, a lack of real means will result in speed reductions and actually changing the regulation into a prescriptive one. Also the relative simplicity of the correction factors for off standard main dimensions and speed in comparison to power prediction methods like Holtrop \& Mennen (Holtrop \& Mennen, 1984), still used today in the conceptual design phase, could result in undesirable speed reductions in some off standard designs typical for RoRo carriers. Then, the consequence will be more ships and/or less products shipped. These questions will be addressed.

Speed reductions based on the minimum social costs per ton-mile, could differ substantially from the speed reductions required to get some designs in line with the EEDI regulations. With other words does this measure reflects the impact of the social costs?

Are the proposed reductions in required power achievable ? If not, speed reduction is the only answer. Is speed reduction defendable? For example the required power for bulk-carriers has dropped with $40 \%$ in 30 years. From this $40 \%, 20 \%$ is achieved by an improvement of the engine performance and the other $20 \%$ by hydrodynamic improvements. (Frouws, 2012) The EEDI regulations require a drop of required power of $25 \%$ in 10 years.

This paper tries to evaluate these aspects looking from the perspectives of the society as well as from the ship-owner.

\section{Methodology}

This study is focusing on Ro-Ro cargo carriers. A ship-type with an interesting variation in main dimension ratios and design speeds. To be able to deal with all the research questions the following information and calculated performance indicators thought to be necessary:

- A description and interpretation from the emissions and there impacts on the environment, in terms of marginal external costs in combination with emission aspects like fund and stock pollutants. But also the possibilities for their abatement.

- Determination from the attained EEDI for a set of 30 diverse existing RoRo cargo carriers from which the information is well known and thoroughly gathered and composed. These attained EEDI's will be set out against the in the future planned reference lines. Secondly the determination of the required speed in order to achieve the attained EEDI planned in 2025. In this way one is testing existing designs in their ability to fulfil the future regulations for new designs.

- Calculation of the costs per ton mile and lane-meter mile at the economic speed per vessel. The economic speed is the speed with the lowest costs per ton mile and/ or lane-meter mile. The port time is set on $40 \%$ of the total time. The calculations are executed with the NPV method and include all costs, except loading discharging costs. The voyage, running and capital costs are modelled as a function of relevant 
parameters from the vessel (Aalbers, 2000). The designs are actually regarded as new buildings. At first the current new-building value is determined afterwards a net present value calculation of all the costs is made per vessel assuming a lifetime of 30 years with $60 \%$ own capital. These calculations were repeated, but then based on the social costs which means an increase in the voyage costs, the latter depends strongly on the speed.

Including the marginal external costs of all emissions is the only way to compare the consequences of emissions from several sources in a consistent way. However, the law deals with these emissions in separate regulations which has the disadvantage that the overall more holistic picture could be lost. By setting the $\mathrm{CO}_{2}$ emission regulation in the total perspective of all emissions makes it easier to judge the quality from the EEDI approach.

There are other aspects which has to be taken into account for example the ease of dealing with a specific emission in combination with the long term effects. This aspect is approached in a more qualitative way.

The economic calculation model used, determines the costs of transport expressed in euro per ton mile using $80 \%$ of the deadweight on average and being in port for $40 \%$ of the time. Also the costs per lane-meter mile are determined based on an average filling rate of $60 \%$ of the available lane-meters and again a port time of $40 \%$ of the year. All the costs who are normally covered by a voyage charter. The existing vessels in the database are regarded as new-buildings in the calculations, despite their age. By this approach and by excluding price effects, a fair design comparison becomes possible. In reality varying second hand prices and sailing profiles can change the real transport costs per ton-mile dramatically.

The used emission rates and marginal external costs applied in these calculations are shown in Table 1.

The external cost rates are averaged values for European sea areas and based on Clean Air for Europe (CAFE) Program 2005. The chosen external costs for CO2 is the lowest estimate, known upper values are at least 80 euro which shows the difficulty in estimating the effects of climate change.

Table 1 Marginal external costs and emission rates as a function of the tons of fuel

\begin{tabular}{|c|c|c|c|c|c|c|c|c|}
\hline \multicolumn{9}{|c|}{ Emission rates per kg or ton fuel and external costs per ton emitted. } \\
\hline $\begin{array}{l}4 \text { stroke diesels } \\
\text { and }\end{array}$ & $\mathrm{CO} 2$ & $\mathrm{SO} 2$ & PM & $\mathrm{HC}$ & $\mathrm{CO}$ & $\mathrm{NO}_{x}$ Tier 1 & $\mathrm{NO}_{x}$ Tier 2 & $\mathrm{CH} 4$ \\
\hline $\begin{array}{l}\text { LNG emission } \\
\text { rates }\end{array}$ & $\begin{array}{l}\text { ton per } \\
\text { ton }\end{array}$ & $\begin{array}{l}\mathrm{kg} \text { per } \\
\text { ton }\end{array}$ & $\begin{array}{l}\mathrm{kg} \text { per } \\
\text { ton }\end{array}$ & $\begin{array}{l}\mathrm{kg} \text { per } \\
\text { ton }\end{array}$ & $\begin{array}{l}\mathrm{kg} \text { per } \\
\text { ton }\end{array}$ & $\begin{array}{l}\mathrm{kg} \text { per } \\
\text { ton }\end{array}$ & $\begin{array}{l}\mathrm{kg} \text { per } \\
\text { ton }\end{array}$ & $\begin{array}{l}\mathrm{kg} \text { per } \\
\text { ton }\end{array}$ \\
\hline $\mathrm{HFO}(2,5 \% \mathrm{~S})$ & 3.114 & 52.5 & 12.5 & 3.33 & 3.33 & 80 & 60 & 0.099 \\
\hline LFO $(0,05 \%$ S) & 3.151 & 1.05 & & 3.33 & 3.33 & 80 & 60 & 0.099 \\
\hline $\begin{array}{l}\mathrm{DO}(\mathrm{MDO}) \\
(0,05 \% \mathrm{~S})\end{array}$ & 3.206 & 1.05 & 2.3 & 3.33 & 3.33 & 80 & 60 & 0.099 \\
\hline $\mathrm{GO}(0,05 \% \mathrm{~S})$ & 2.750 & 1.05 & & 3.33 & 3.33 & 80 & 60 & 0.099 \\
\hline LNG pure & 3.000 & & & 3.23 & 8.39 & 8.4 & & 50 \\
\hline $\begin{array}{l}\text { LNG/DO (4 till } \\
6 \% \text { DO) }\end{array}$ & 2.780 & & 0.6 & 3.13 & 8.13 & 60 & & 50 \\
\hline $\begin{array}{l}\text { External costs/ } \\
\text { ton }\end{array}$ & $€ 15$ & $€ 6000$ & $€ 12000$ & $€ 2000$ & $€ 22$ & $€ 4900$ & $€ 4900$ & $€ 2000$ \\
\hline
\end{tabular}


In order to make a fair economic comparison between the designs it is important to determine those speeds where the costs per ton mile or lane-meter mile are the lowest. Which is defined here as the economic speed. Otherwise the effects of large design speed variations in the database would prevail.

There is a balance between the capex and opex. Where the opex will increase exponentially per ton-mile with increasing speed, the capex per ton-mile will decrease. The economic optimum speed is determined enabling us to compare the designs in their economic optimum operational performance.

\section{Results}

\section{Emissions}

The considerations and calculations below are based on HFO as main engine fuel and MGO for the auxiliaries. These fuels when burned in an engine tend to emit $\mathrm{CO}_{2}, \mathrm{SO}_{2}$, $\mathrm{PM}, \mathrm{HC}, \mathrm{CO}$ and $\mathrm{NO}_{\mathrm{x}}$. The Sulphur content of HFO is assumed to be 2,5\%. The PM emission is strongly coupled to the Sulphur content. Table 2 shows the share of certain emission combinations in the external costs as a percentage of the fuel costs (average). the fuel costs are based on figures from April 2015. The $\mathrm{NO}_{\mathrm{X}}$ emission rates on Tier 2 maximum allowable emission. (see Table 1 )

The external costs of the $\mathrm{SO}_{\mathrm{x}}$ and $\mathrm{NO}_{\mathrm{x}}$ emissions are larger than the external costs of $\mathrm{CO}_{2}$ emissions. Partly due to the low estimation applied. The $\mathrm{SO}_{\mathrm{x}}$ and $\mathrm{NO}_{\mathrm{x}}$ emissions are dealt with in the regulations in Sulphur Emission Control Areas (SECA) and/ or Emission Control Areas (ECA), the $\mathrm{CO}_{2}$ emissions are worldwide approached. The reason is that the acid rain problem $\left(\mathrm{SO}_{\mathrm{x}}\right.$ and $\left.\mathrm{NO}_{\mathrm{x}}\right)$ is more locally oriented than the GHG emissions like $\mathrm{CO}_{\mathrm{x}}$ and methane. It has to be kept in mind that the used external cost figures are based on the estimations of the consequences of emissions at sea in the coastal areas from Europe. The majority of the costs included are on shore, where the fund pollutants tend to change in stock pollutants.

Many people have forgotten that the acid rain problem in the 70's was largely solved by a cap and trade approach resulting in for example replacing the sulphur containing coal as a fuel and/or the application of sulphur scrubbers in the shore based power plants in combination with SCR systems to abate the $\mathrm{NO}_{\mathrm{x}}$ emissions. With other words reversible till a certain height.

The $\mathrm{CO}_{2}$ emissions, the cause of climate change, cannot be reduced easily. Burning hydrocarbons means $\mathrm{CO}_{2}$ emissions. This tends to become a major problem. Emitting $\mathrm{CO}_{2}$ in huge amounts since 1800 has increased the content of $\mathrm{CO}_{2}$ in the atmosphere. The combination of an increasing world population, a decreasing usable agricultural area and water shortages due to the GHG effects is not a fine perspective and tends to increase the marginal costs substantially in the future.

Table 2 Average external costs as a function of the average fuel costs

\begin{tabular}{llll}
\hline $\begin{array}{l}\text { External costs all emissions as a perc. of the fuel } \\
\text { costs }\end{array}$ & $\begin{array}{l}\text { Excluding SOx and } \\
\mathrm{PM}\end{array}$ & $\begin{array}{l}\text { Excluding SOx, NOx and } \\
\mathrm{PM}\end{array}$ & $\mathrm{CO}_{2}$ \\
\hline $224 \%$ & $99 \%$ & $15 \%$ & $13 \%$ \\
Price HFO & $€ 335.00$ & & \\
Price MGO & $€ 565.00$ & & \\
\hline
\end{tabular}


The EEDI will lower the acceleration of the emissions but not decrease the flowrate. The study from the IMO (Bazari \& Longva, 2011), page 24, shows clearly that the emission rate is not expected to decrease because of the estimated required hydrocarbon fuel to serve the world population.

\section{The "attained EEDI" for the dataset of existing vessels}

The dataset used is based on multiple sources, for example (RINA 1990 to RINA 2011), several publications about these vessels, internet sources and is believed to be as precise as possible for publicly available information sources. The combinations of design speed and required power are based on the given information of the corresponding percentage of the MCR of the main engine, often $90 \%$ and the, in the design applied sea margin of mostly $15 \%$.

In other words, the design speed in the database is reached with approximately $75 \%$ of the MCR. The attained EEDI calculation requires $75 \%$ sharp. Figure 1 shows the calculated attained EEDI's for the dataset based on the design speeds.

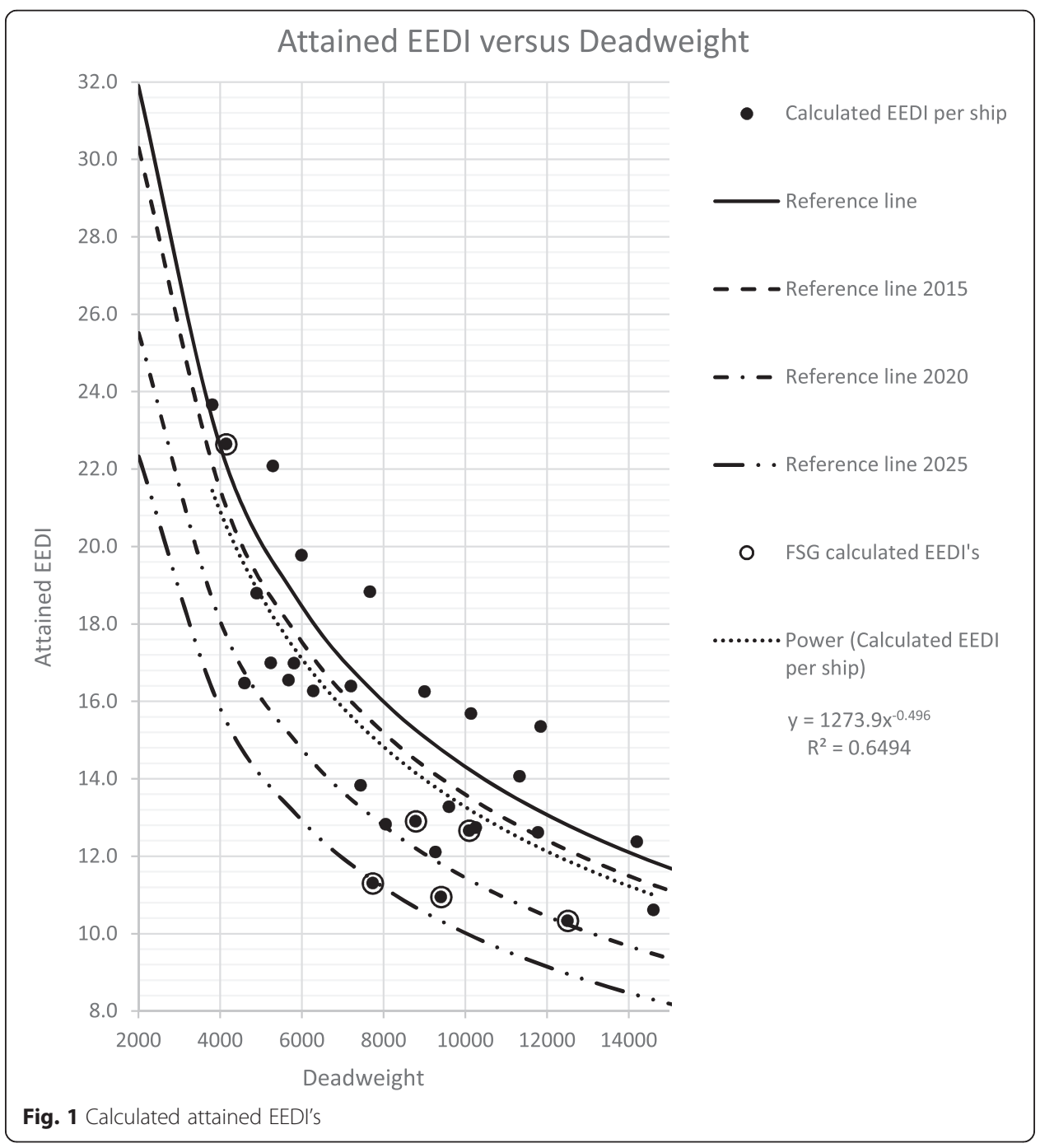


In the figure are 6 vessels designed and build by the Flensburger SchiffbauGesellschaft. Several publications about their design process are used to get the database correct. The publication about the 142 meter vessel with 4140 ton deadweight is one of them. (Tobias Haack, 2009) This vessel is off standard in terms of the number of decks(4) in relation to its length, more decks require a certain breadth. It had to be short and wide because of the size of the berth in the port. On the other hand the research during the design phase involved substantial CFD calculations in order to improve the fuel consumption. The attained EEDI for this off standard design is not good. An identical design in 2025 should have an EEDI just below 16 instead of the attained EEDI of close to 23 . This should mean a power reduction of $30 \%$ or a speed reduction of 3,6 knots in order to comply. Its design speed was 21,6 knots to keep up with the required schedule. A power reduction of $30 \%$ is not realistic taking into account the effort already taken to reduce its fuel consumption. It seems that off standard length breadth and deadweight volume ratios are not taken into account correctly by the attained EEDI calculations. It should be realised that one of the major reasons of this low EEDI is the fact that the EEDI is based on the deadweight while this vessel, in this trade, is more oriented on selling lane-meters which increases the "garage" volume while increasing its lightweight and decreasing its deadweight.

The reference line 2015 is achieved easily by the majority of the designs, indicating that the remarks made in the assessment of the EEDI (Bazari \& Longva, 2011) are correct. They state that $30 \%$ reduction will be achievable, at first because the starting reference line is above the average and secondly that there are enough possibilities to improve the designs. Looking to the performance of the FSG vessels it seems that it is more the application of the available knowledge that can do the job than a "to be expected innovation". However, the rate of improvement required by the reference line of 2025 is without radical innovation not foreseeable in the future after 2025.

The EEDI, if well applied will mainly force the ship-owners to design the vessels according the state of the art. If that recipe does not work anymore, there is only one alternative, speed reduction.

The question can also be considered from a different point of view. Which design speed should be necessary to reach the 2025 EEDI level? The results of these calculations are summarised in Fig. 2.

The balls reflect the original design speed. The triangles the required speed in order to comply with the 2025 reference line from the EEDI.

There is one current vessel that does not require a speed reduction, that design is from FSG.

The average required speed reduction is 2,74 knots with an original average speed of 20.49 knots, this results in a new average speed of 17,75 knots. May be positive from the environmental point of view but on the other hand, it will influence the schedules. As soon as the latter aspect influences the competitiveness with, for example, trucks it could be questionable in terms of overall environmental effect. The variance in design speed is mainly due to schedule requirements, for example daylight operations or just night operations for sleeping truck drivers. For this vessel type it could be sometimes wiser to exclude design speed considerations in the attained EEDI.

This graph shows also the large spread in the design speeds indicating the very different design goals as a result of the different businesses served. 


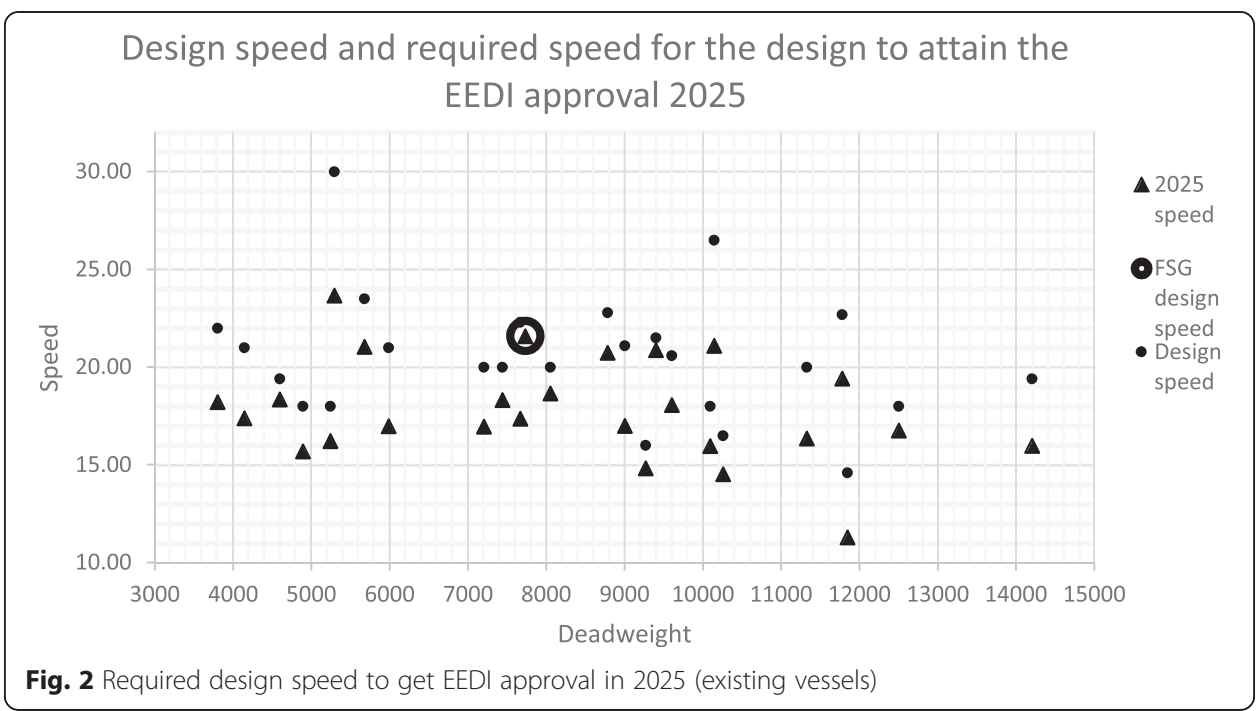

\section{Economic considerations}

The economic calculations of the marginal private and social costs are summarised in Fig. 3. The cost items involved are based on the costs covered by voyage charters. It has to be realised that these calculations are executed at the economic speed which are different in the case of private costs or social costs. So, the transport carrying capacity per year is different.

Figure 3 indicates clearly the substantial impact of the marginal external costs on top of the marginal private costs. Secondly it has to be realised that these costs are achieved at the economic speeds.

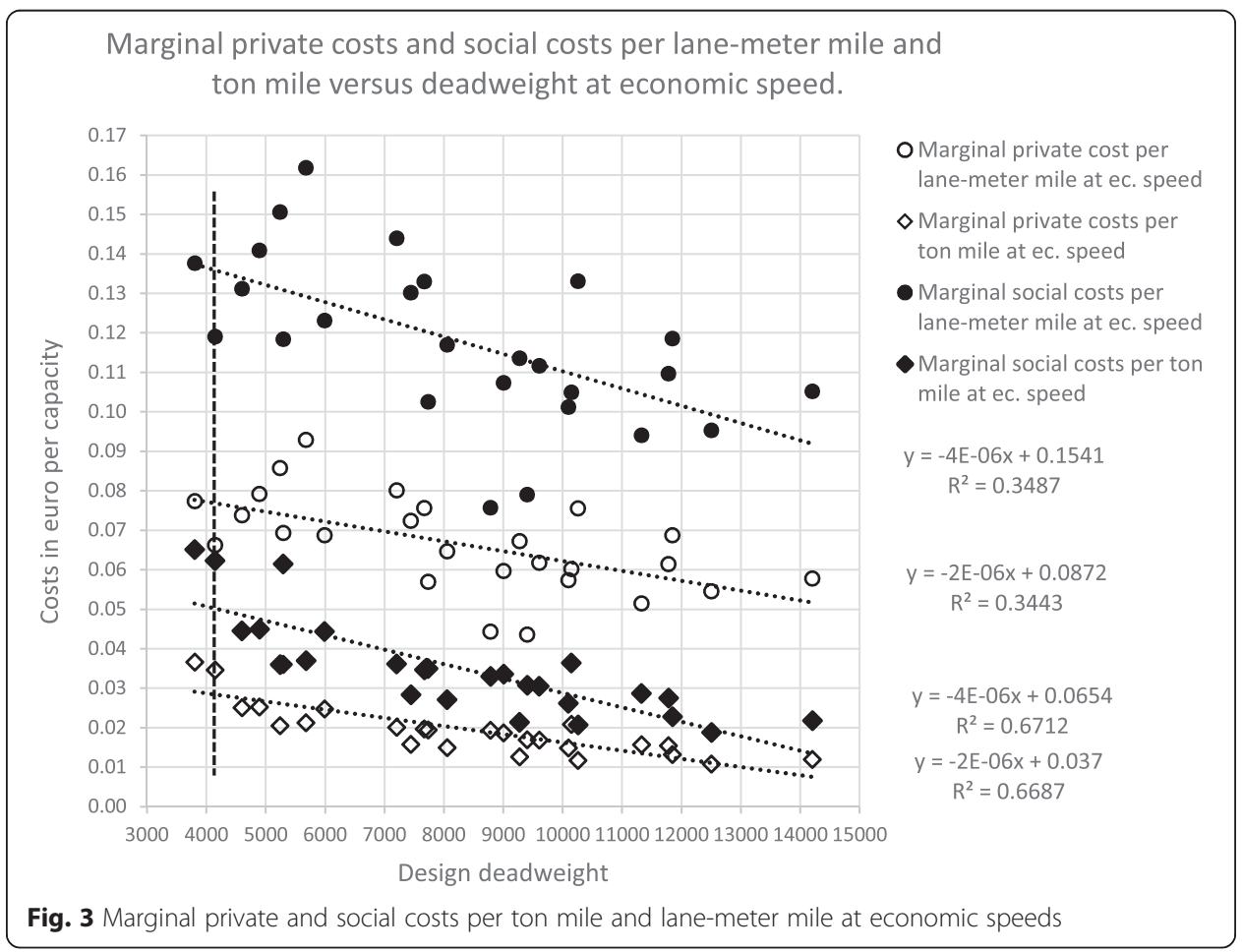


For a ship type the EEDI will be based on one type of "capacity", normally tons deadweight or volume, the latter is proportional to lane-meters in the case of RoRo carriers. Taking again the $142 \mathrm{~m}$ design as discussed at Fig. 1 (Tobias Haack, 2009) (see vertical dotted line) some remarkable effects can be seen. Both, marginal private and social costs per ton mile are relative high, the marginal costs per lane-meter mile are however extremely low and even in comparison to larger vessels. In combination with Fig. 2 you can conclude that such a design in 2025 will be forced to increase its private costs by decreasing its design speed from 21 knots to 17 knots based on the EEDI. The economic speed from this vessel based on marginal private costs is 19.5 knots and based on social costs a merely 13.3 knots. (see Fig. 4) This line service is a connection between Ireland and England, the schedule is dictated by logistical reasons.

The corresponding economic speeds at private and social costs are shown in Fig. 4. The economic speeds are determined by means of an iteration in order to find the speed with the lowest overall costs per ton mile. The calculated economic speed based on the marginal social costs is on average $72 \%$ from the economic speed based on the marginal private costs. This means that from the societal point of view a speed reduction from around $25 \%$ is defendable. The average economic speed of the vessels in the database based on private costs is 19,08 knots, based on social costs 13,6 knots, a difference of 5.48 knots. The difference with the speed reduction as a result of the EEDI, 2.74 knots, is large. Due to the exponential increase of fuel consumption with speed, the difference will be substantial in terms of fuel consumption. Speeds based on the social costs will require roughly $30 \%$ more vessels to get the same transport capacity.

\section{Conclusions}

The perspective from the societal point of view differs strongly from the private cost point of view from the ship-owner. The EEDI approach helps, but as long as the external costs are not really included in the cost equations the right decisions in terms of design and operational speed or required investments to avoid emissions will not be taken.

The external costs are mainly based on the acidifying emissions, not on GHG related emissions. The low chosen external costs of the $\mathrm{CO}_{2}$ emissions are $13 \%$ of the fuel costs and as a result has a limited effect on the economic speed based on the social

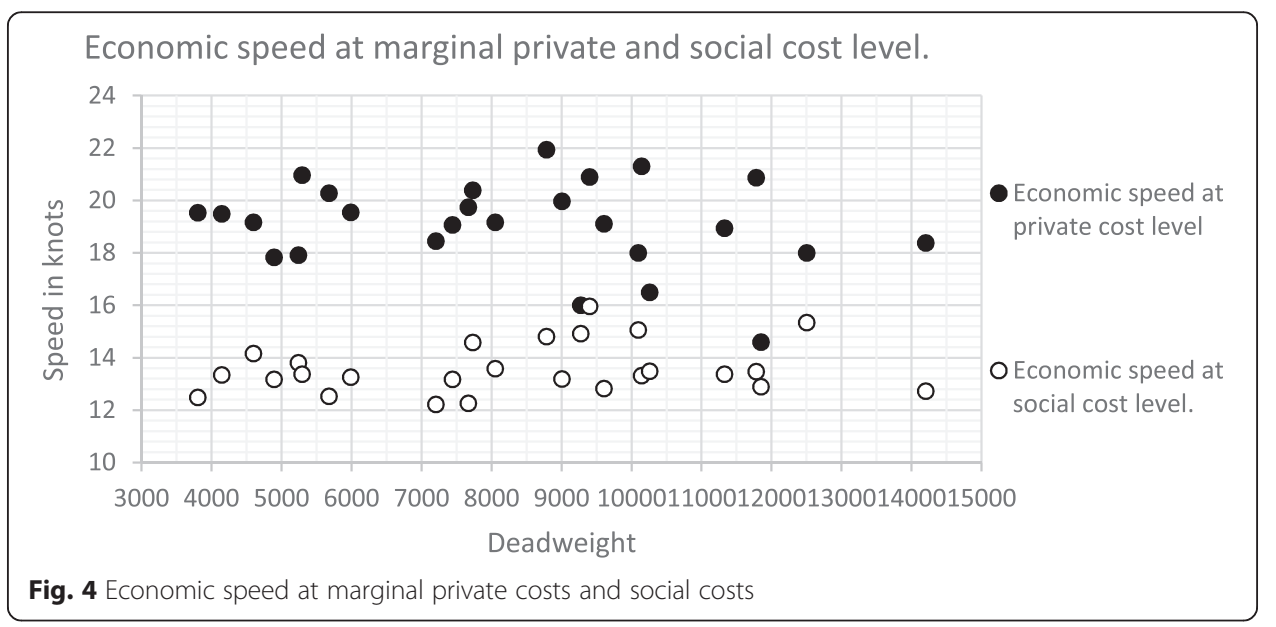


costs. However, it is extremely difficult to reverse the usage of hydrocarbons as a fuel in shipping, due to the required energy density. So, a substantial increase in marginal external cost of $\mathrm{CO}_{2}$ emissions can be expected. This makes a straight forward comparison only based on current marginal external costs between GHG related emissions (Stock pollutants) and acidifying emissions (Fund pollutants) not credible while looking to all these aspects.

When on board measures are taken abating acidifying emissions and health threatening emissions the required speed reductions to reduce the social costs can be limited. Further research is required on this aspect. However at this moment there are no requirements outside the SECA area's.

A new calculation method taking into account the threat of the different emissions in the future based on forecasts could help to value and judge the situation. Especially because the NPV method applied did not take into account the expected raise in the marginal costs nor the expected impact of these emissions after the ship will be scrapped.

This study seems to give good reasons to charge the external costs to the shipowners. That could help to solve the problem of the acidifying emissions. However, it does not much in the field of decreasing the $\mathrm{CO}_{2}$ emissions and as a result the $\mathrm{CO}_{2}$ content of the atmosphere. A situation, hardly to reverse, but also difficult in its abatements possibilities. One could reduce the emission per ton deadweight, but the tons are still increasing.

The EEDI reference lines as proposed in 2025 are most likely achievable. On the other hand the suggested improvement with $30 \%$ is misleading. The major gain will be forcing designers to apply the state of the art in their designs and/or in combination with speed reductions. Speed reduction can be wrong when the competiveness with other more emitting transport modalities suffers.

The EEDI system seems to punish "off standard" designs in terms of main dimension ratio's and or high design speed. That can be counterproductive from the environmental point of view in specific logistical situations, especially when competing with other modalities, but also if one off standard ship can replace two standard ships. This could be solved by allowing alternatives like the method of the 'Environmental Impact Statement' in those cases where the overall environmental performance will improve.

Separately dealing in the regulations with different kinds of emissions decreases the potential growth of the application of LNG as a fuel. This fuel is favourable for sulphur, $\mathrm{NO}_{\mathrm{x}}, \mathrm{PM}$ and $\mathrm{CO}_{2}$ emissions. Its use is financially mainly credited in SECA areas. In other areas it will only enable higher speeds because of the lower attained EEDI, actually areas where higher speeds are less important because the schedule problems are less.

The focus of the EEDI regulations on the design speed of the vessel underestimates the possible reductions of the fuel consumption at lower speeds. For example The current practice of running the controllable pitch propeller on a constant rpm because of the PTO lowers the propeller efficiency substantially at lower speeds. 
Authors' contribution

The author declares that he has collected all the data and made all the calculation models behind the results presented in the paper and that he has written this paper without the help of co-authors besides a language check and the work from the reviewers.

\section{Competing interest}

I declare that there are no financial neither non-financial competing interests as indicated today February 2, 2016 in your description of competing interests on the site from the Journal Shipping and Trade in relation to this paper.

Received: 19 October 2015 Accepted: 22 May 2016

Published online: 31 August 2016

\section{References}

Aalbers, A. (2000). Evaluation of Ship Design Alternatives. Proceedings of the 34th Wegemt School, June. Delft, the Netherlands.

Bazari Z, Longva T (2011) Assessment of imo mandated energy efficiency measures for international shipping. IMO, London

Frouws, K. (2012). Benchmarking existing and new designs. Napels, NAV 2012

Germanische L (2013) Guidelines for Determination of the Energy Efficiency Design Index. Germanische Loyd, Hamburg

Holtrop, J., \& Mennen, G. (1984). An Approximate Power Prediction Method. International Ship_building Progress, Vol. 31.

RINA. (1990 to 2011). The Significant Ships 1990 to 2011. The Royal Institute of Naval Architects

Tobias Haack, Stefan Krüger, Hendrik Vorhölter (2009) Optimisation of a fast monohull with CFD-methods. 10th International Conference on Fast Sea Transportation FAST 2009. Athens, Greece, National Technical University of Athens

Submit your manuscript to a SpringerOpen ${ }^{\odot}$ journal and benefit from:

- Convenient online submission

- Rigorous peer review

- Immediate publication on acceptance

Open access: articles freely available online

- High visibility within the field

- Retaining the copyright to your article

Submit your next manuscript at $>$ springeropen.com 